\title{
Predictable climate impacts of the decadal changes in the ocean in the 1990s
}

\section{Article}

Published Version

Robson, J., Sutton, R. and Smith, D. (2013) Predictable climate impacts of the decadal changes in the ocean in the 1990s. Journal of Climate, 26 (17). pp. 6329-6339. ISSN 15200442 doi: https://doi.org/10.1175/JCLI-D-12-00827.1 Available at https://centaur.reading.ac.uk/33649/

It is advisable to refer to the publisher's version if you intend to cite from the work. See Guidance on citing.

To link to this article DOI: http://dx.doi.org/10.1175/JCLI-D-12-00827.1

Publisher: American Meteorological Society

All outputs in CentAUR are protected by Intellectual Property Rights law, including copyright law. Copyright and IPR is retained by the creators or other copyright holders. Terms and conditions for use of this material are defined in the End User Agreement.

\section{www.reading.ac.uk/centaur}

\section{CentAUR}

Central Archive at the University of Reading

Reading's research outputs online 


\title{
Predictable Climate Impacts of the Decadal Changes in the Ocean in the 1990s
}

\author{
JON ROBSON AND ROWAN SUTTON \\ National Centre for Atmospheric Science_Climate Directorate, Department of Meteorology, University of Reading, \\ Reading, United Kingdom \\ DOUG SMITH \\ Met Office Hadley Centre, Exeter, United Kingdom
}

(Manuscript received 23 November 2013, in final form 20 February 2013)

\begin{abstract}
During the 1990s there was a major change in the state of the world's oceans. In particular, the North Atlantic underwent a rapid warming, with sea surface temperatures (SSTs) in the subpolar gyre region increasing by $1^{\circ} \mathrm{C}$ in just a few years. Associated with the changes in SST patterns were changes in the surface climate, in particular, a tendency for warm and dry conditions over areas of North America in all seasons, and warm springs and wet summers over areas of Europe. Here, the extent to which a climate prediction system initialized using observations of the ocean state is able to capture the observed changes in seasonal mean surface climate is investigated. Rather than examining predictions of the mid-1990s North Atlantic warming event itself, this study compares hindcasts started before and after the warming, relative to hindcasts that do not assimilate information. It is demonstrated that the hindcasts capture many aspects of the observed changes in seasonal mean surface climate, especially in North, South, and Central America and in Europe. Furthermore, the prediction system retains skill beyond the first year. Finally, it is shown that, in addition to memory of Atlantic SSTs, successfully predicting Pacific SSTs was likely important for the hindcasts to predict surface climate over North America.
\end{abstract}

\section{Introduction}

The goal of decadal climate prediction is to improve the skill of climate projections by initializing climate models using observations. This field has recently received rapid growth in attention (Smith et al. 2007; Pohlmann et al. 2009; Meehl et al. 2009). Many studies have demonstrated skill in predictions of sea surface temperatures (SSTs) and related ocean variables (Keenlyside et al. 2008; Smith et al. 2010; Robson 2010). However, there is much less evidence for skill in predicting societally relevant climate variables over land (Kim et al. 2012; van Oldenborgh et al. 2012; MacLeod et al. 2012). In some ways this is surprising, given the evidence that decadal variability in SST modulates the surface climate in many regions of the world. For example, many studies suggest that North Atlantic SSTs modulate surface

Corresponding author address: Jon Robson, Department of Meteorology, University of Reading, Earley Gate, P.O. Box 243, Reading RG6 6BB, United Kingdom.

E-mail: j.i.robson@reading.ac.uk temperature and rainfall in the tropical North Atlantic, Africa, Europe, and the Americas (Sutton and Hodson 2005, 2007; Knight et al. 2006; Zhang and Delworth 2006; Kushnir et al. 2010; Sutton and Dong 2012). It is also well established that multidecadal variability in Pacific SSTs-for example, the interdecadal Pacific oscillation (IPO; Power et al. 1999) — can affect the climate in many regions, especially droughts and flooding in North America (Seager et al. 2005b; Schubert et al. 2004, 2009; Meehl and Hu 2006; Wang et al. 2009; Dai 2013).

One of the challenges in the development and evaluation of decadal prediction systems is that the low frequency of the variations of interest-and short observational records-create serious problems of sampling when assessing skill. Faced by this problem, one approach is to focus on case studies rather than average skill scores. Case studies can be selected to identify situations in which the signal-to-noise ratio of decadal changes is relatively high, making it easier to identify robust influences and elucidate the mechanisms involved. This approach has been used successfully to demonstrate and understand the predictability of the rapid 
warming of the North Atlantic Ocean in the 1990s (Robson et al. 2012a,b; Yeager et al. 2012) and has also been used to examine shifts in Pacific SST (Meehl and Teng 2012).

During the mid-1990s, North Atlantic SSTs warmed very rapidly (Robson et al. 2012a). Previous studies have established that initialized decadal predictions could have predicted this event (Robson et al. 2012b; Yeager et al. 2012). However, a key question is whether changes in climate over land that appear to be related to this ocean warming (e.g., Sutton and Dong 2012) could also have been predicted. Some evidence that this is the case was provided by Robson et al. (2012b) using hindcasts made with Met Office decadal prediction system (DePreSys, also referred to in this paper as DeP; Smith et al. 2007). However, Robson et al. (2012b) only examined the mean impact from March to November, whereas important seasonally dependent differences are expected (Sutton and Hodson 2007; Sutton and Dong 2012). Given the potential societal importance of decadal predictions over land, we build on Robson et al. (2012b) by investigating the seasonal climate impacts of the mid-1990s Atlantic warming. To do so, we examine the differences between hindcasts initialized before and after the warming, relative to hindcasts initialized without the use of observations, in contrast to the focus of Robson et al. (2012b) of whether the warming itself was predictable. We address two specific questions: (i) Does initialization with observations affect the predicted seasonal mean surface climate variables associated with the Atlantic warming event? and (ii) Do the predicted changes in seasonal mean surface climate agree with those observed? The article is organized as follows: the methodology is outlined in section 2 , and the results are presented and discussed in sections 3 and 4. Finally, the main conclusions are summarized in section 5 .

\section{Data and methods}

\section{a. DePreSys}

This study examines the perturbed physics ensemble version of DePreSys (Smith et al. 2010), which uses nine variants of the third climate configuration of the Met Office Unified Model (HadCM3) (one standard and eight with perturbed parameters) to represent some model uncertainty in predictions (Collins et al. 2006). The parameter perturbations introduce radiative imbalances to the models, and so flux adjustments are used to maintain a realistic climatology for SST and surface salinity [see Collins et al. (2006) for details]. Nine-member ensemble hindcasts (one member per model version) start every November from 1960 to 2005 after observed anomalies are assimilated into the ocean and atmosphere. More specifically, anomalies are computed from precalculated gridded datasets for the ocean (3D temperature and salinity from the Met Office ocean analysis; Smith and Murphy 2007) and atmosphere [3D winds, 3D temperature, and sea level pressure from the 40-yr European Centre for Medium-Range Weather Forecasts (ECMWF) ReAnalysis (ERA-40); Uppala et al. 2005] and are assimilated by relaxing the model to its own climatology plus the observed anomalies. The ocean and atmosphere climatologies are defined as 1951-2006 and 1958-2001, respectively, and are calculated from each model's (flux corrected) free-running transient simulation. Hindcasts are forced with (historical) anthropogenic and (projected) natural forcings. More specifically, total solar irradiance is assumed to follow the previous 11-yr solar cycle, and initial volcanic aerosol was reduced to zero with an $e$-folding time scale of $1 \mathrm{yr}$ (i.e., no future eruptions). The sulfur cycle is simulated interactively, driven by emissions of sulfur dioxide; the direct and first indirect effect of sulfate aerosols are represented (Johns et al. 2003). After 2000, the Special Report on Emissions Scenarios (SRES) A1B is used.

A control experiment is also performed (NoAssim, also referred to in this paper as NoA). NoAssim is identical to DePreSys (i.e., nine-member ensembles), except the initial conditions are taken from the free-running transient simulations (using the same model variants as DePreSys), which were initialized in preindustrial conditions and forced with historical anthropogenic and natural forcings. A full description of DePreSys and NoAssim is found in Smith et al. (2010).

\section{b. Comparison method}

Figure 1a shows the warming of North Atlantic SSTs $\left(35^{\circ}-65^{\circ} \mathrm{N}\right)$ in the mid-1990s, by $0.8^{\circ} \mathrm{C}$ in just a few years. The mid-1990s warming is captured by DePreSys (see 1994 hindcast in Fig. 1a), but not by NoAssim. NoAssim predicts a slow warming trend and does not capture the magnitude of the multidecadal variability in SST. To assess the seasonal climate impacts of the rapid warming of the North Atlantic predicted by DePreSys, hindcasts that start before and after the warming of the North Atlantic are compared. More specifically, for each season the difference in hindcasts started between 1997 and 2005 (warm Atlantic following warming) and hindcasts started between 1968 and 1990 (cold Atlantic before warming) is calculated (gray shading in Fig. 1a highlights time periods used). ${ }^{1}$ Moreover, we assess the impact of initialization by

\footnotetext{
${ }^{1}$ Hindcasts for 1991-96 are not used, as they predict a warming of Atlantic SSTs (Robson et al. 2012b).
} 
a) North Atlantic $\left(35-65^{\circ} \mathrm{N}\right) \mathrm{SST}$

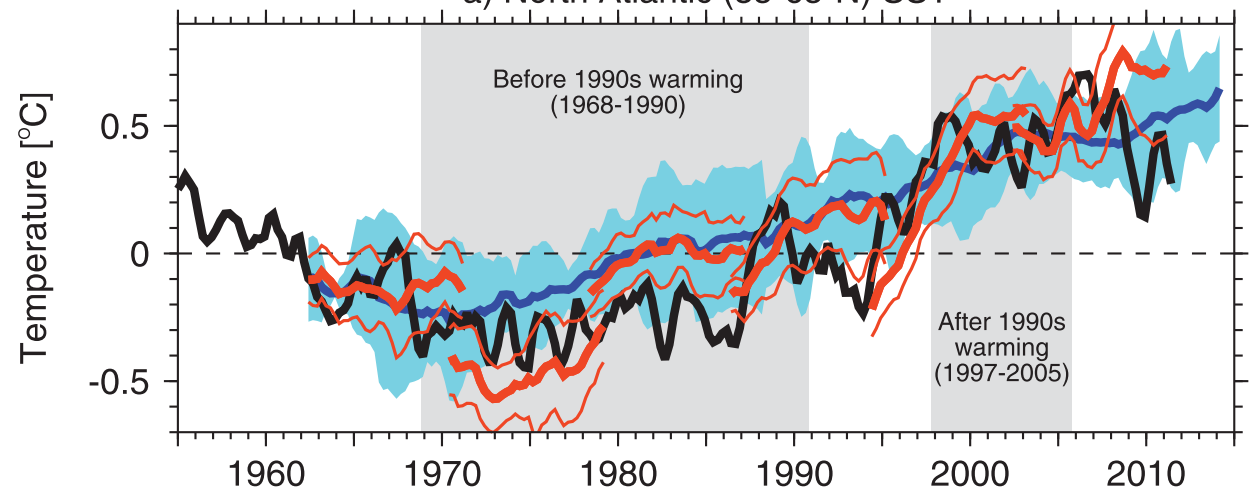

b) SST (Obs 1997:2005 - 1968:1990)

c) SST (Obs 1999:2009 - 1970:1994)
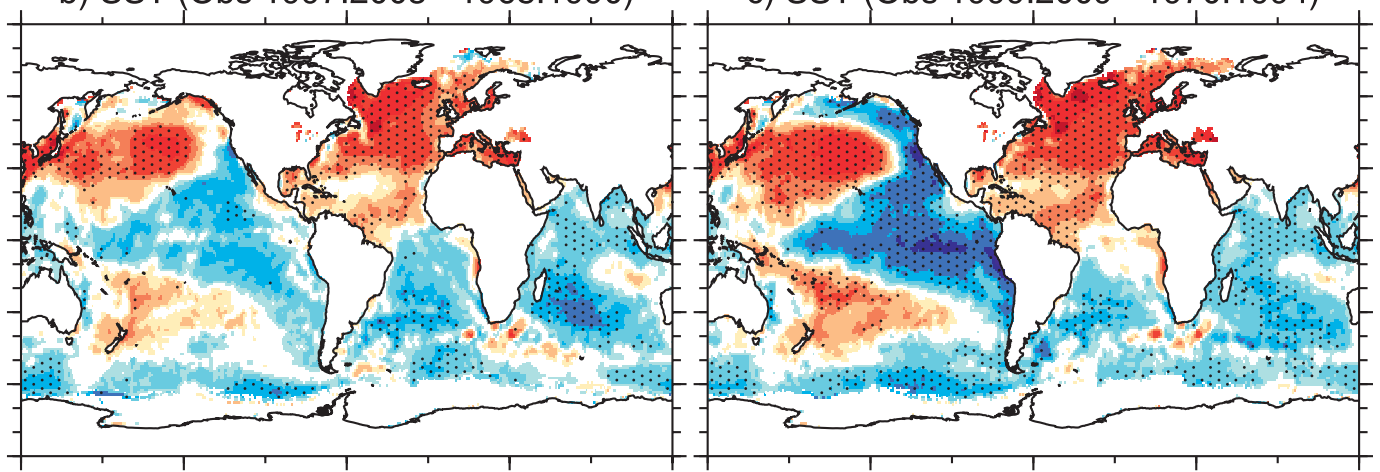

d) SST (DeP-NoA) year 1

e) SST (DeP-NoA) years 2-6

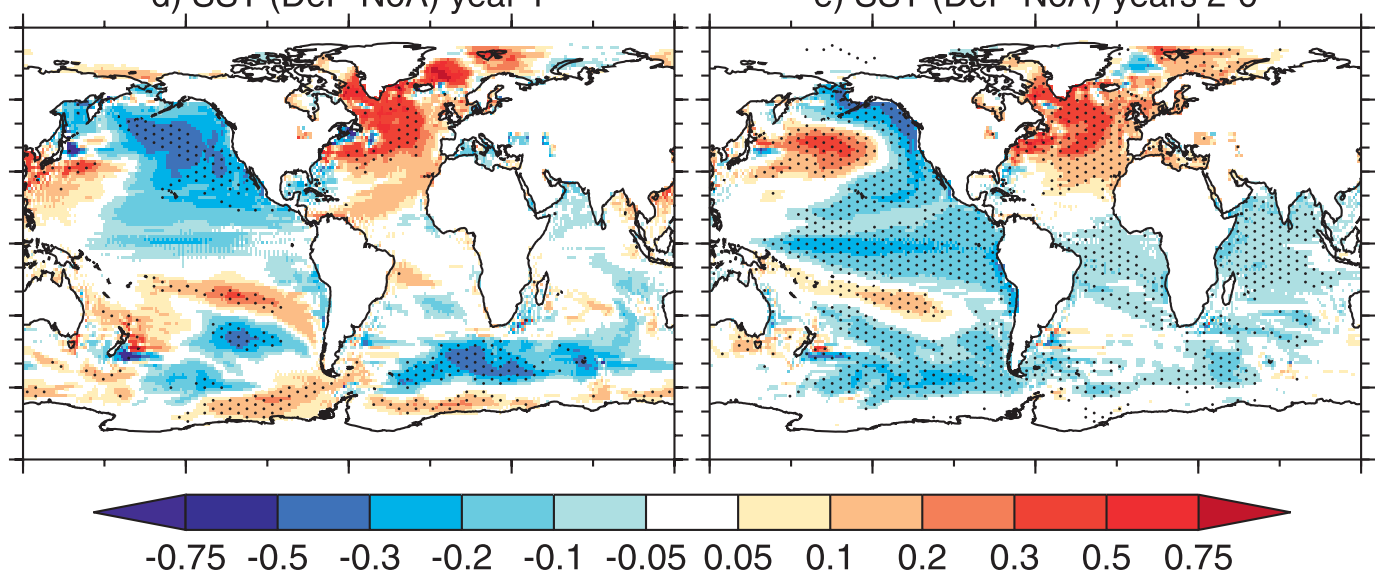

FIG. 1. Comparison of the observed and modeled change in SST $\left({ }^{\circ} \mathrm{C}\right)$ associated with the mid-1990s warming of the North Atlantic. (a) Black line denotes rolling annual mean time series of the observed and predicted SST in the North Atlantic between $35^{\circ}$ and $65^{\circ} \mathrm{N}$. Blue line shows the average of all NoAssim hindcasts, which represents the forced projections of SST, and the blue shading denotes the $1 \sigma$ spread of NoAssim. Red lines show DePreSys hindcasts initialized in November 1962, 1970, 1978, 1986, 1994, and 2002, where the thick and thin lines denote the ensemble mean and $95 \%$ confidence interval, respectively. Gray shading highlights the start times used to compare hindcasts made before and after the mid-1990s warming of the North Atlantic. (b) Difference in annual mean SST before and after the mid-1990s warming of the North Atlantic (i.e., 1997-2005 minus 1968-90), calculated from the HadISST dataset. (c) As in (b), but for 1999-2009 minus 1970-94, and is the validation of the DePreSys SST difference in (e). Note that (b) and (c) have been detrended at each grid point—-see text. (d) SST averaged over year 1 from DePreSys hindcasts initialized in 1997-2005 minus the SST averaged over year 1 of hindcasts initialized in 1968-90. Difference in DePreSys is made relative to the same difference in NoAssim. (e) As in (d), but for years 2-6. Stippling shows where the differences are significant at the $p \leq 0.1$ level based on a two-sided Student's $t$ test. 
comparing the difference in DePreSys ( $\Delta$ DePreSys) relative to the same difference in NoAssim (i.e., $\Delta$ DePreSys $\Delta$ NoAssim), which removes externally forced changes from DePreSys. More specifically for clarity, for a variable $V$ we compare the difference $\left(\bar{V}_{\mathrm{DeP}}^{1997-2005}-\bar{V}_{\mathrm{DeP}}^{1968-90}\right)-$ $\left(\bar{V}_{\text {NoA }}^{1997-2005}-\bar{V}_{\text {NoA }}^{1968-90}\right)$, where $\bar{V}_{\text {DeP }}\left(\bar{V}_{\text {NoA }}\right)$ defines the average of all DePreSys (NoAssim) hindcasts started over the period shown in superscript.

Figure $1 \mathrm{~b}$ shows the mean difference in observed SST between the two periods after a trend is removed from each grid point (see below). To the extent that the external forcing can be removed by detrending, this shows the difference in DePreSys initial conditions. Thus, the hindcasts initialized between 1997 and 2005 are initialized significantly warmer in the North Atlantic, especially in the North Atlantic subpolar gyre. Warm anomalies are also present in the northwestern Pacific and weak cool anomalies are present in the equatorial tropical Pacific, but the latter are not significant. Our analysis assesses the impact of these initial differences in ocean conditions (including those beneath the surface, not shown) on the subsequent evolution of the climate system.

Finally, to reduce the effects of unpredictable variability, surface variables are averaged over multiyear periods. Specifically, the focus is on forecast years 2-6 to highlight where the impact of initialization remains beyond forecast year 1. Differences are tested for significance using a two-sided Student's $t$ test after the degrees of freedom are reduced to take account of the serial correlation in consecutive NoAssim hindcasts as a function of forecast lead time (Zwiers and von Storch 1995; Robson et al. 2012b). Note that taking the difference between hindcasts started in the two periods but, for the same lead times, overcomes the need to define a model climatology (from which to express anomalies) or for mean bias corrections.

The modeled changes are also compared with the observed changes in SST [from the Hadley Centre Sea Ice and SST dataset (HadISST); Rayner et al. 2003], sea level pressure [SLP, from the Hadley Centre SLP dataset, version 2 (HadSLP2); Allan and Ansell 2006], surface air temperature, and precipitation [SAT and Precip, respectively, from the Climatic Research Unit Time Series, version 3.1 (CRU TS3.1); Mitchell and Jones 2005]. Removing the difference in NoAssim from the difference in DePreSys removes the forced change. Therefore, for the comparison, an estimate of the forced change is also removed from all observations at each grid point by fitting a linear regression to the rolling 3-yr-average global mean $\left(60^{\circ} \mathrm{S}-75^{\circ} \mathrm{N}\right) \mathrm{SST}$ over the period $1949-2009$ (the common time period of all datasets). However, note that the detrending will not remove regional forcings (e.g., anthropogenic aerosols; Forster et al. 2007; Booth et al. 2012). We investigated sensitivity to other detrending methods (e.g., quadratic) or the end points and found that the magnitude of the SST and SAT anomalies is sensitive to the details of detrending, but the patterns of anomalies are broadly similar (not shown). Note that SLP and precipitation anomalies are not sensitive to the detrending. Finally, it is worth highlighting that we should not expect the model and observations to agree perfectly, because we are comparing a single realization with the mean of hundreds of model predictions.

\section{Results}

\section{a. Sea surface temperatures}

Figure 1e shows the difference in years 2-6 SSTs between hindcasts initialized before and after the mid1990s warming. Warm SST anomalies are still present in the extratropical North Atlantic, highlighting the memory of the North Atlantic, but they do not remain in the tropical North Atlantic. In the Pacific, DePreSys predicts significant cool anomalies in the eastern and tropical Pacific, and warm anomalies in the northwestern Pacific. Although a similar, but weaker, pattern of $\mathrm{Pa}-$ cific SSTs is present in the initial conditions (Fig. 1a), the SST anomalies grow through the DePreSys hindcasts [cf. years 2-6 (Fig. 1e) with year 1 (Fig. 1d)] and peak in year 5 (not shown). Cool anomalies are also present in the Indian Ocean, the southern tropical Atlantic, and the Southern Ocean.

The difference in years 2-6 SSTs in DePreSys hindcasts initialized before and after the mid-1990s warming is remarkably similar to the observed changes in SST for the validation period (1999-2009 minus $1970-94 ;^{2}$ see Fig. 1c). In the observations, the North Atlantic Ocean remains significantly warm. In the Pacific, cool anomalies intensify in the eastern tropical Pacific, and warm anomalies are present in the northwestern Pacific. Although decadal Pacific SST anomalies are sensitive to the irregularity of the El Niño-Southern Oscillation (Newman et al. 2003; Wittenberg 2009), the anomalies in Fig. 1c are consistent with other studies that suggest a shift in the wider Pacific state occurred in the late 1990s (Peterson and Schwing 2003; Burgman et al. 2008; Chen et al. 2008; Lee and McPhaden 2008). The successful prediction of the development of SST anomalies in the Pacific in the late 1990s, and early 2000s, is consistent with the studies showing skill in this region (Mochizuki et al. 2010, 2012; Meehl and Teng 2012).

\footnotetext{
${ }^{2}$ Note that the observed comparison in Fig. 1c excludes years close to the observed warming (i.e., 1995 or 1996), and ends in 2009 because CRU TS3.1 data end in 2009.
} 
a) DJF TEMP (DeP-NoA)

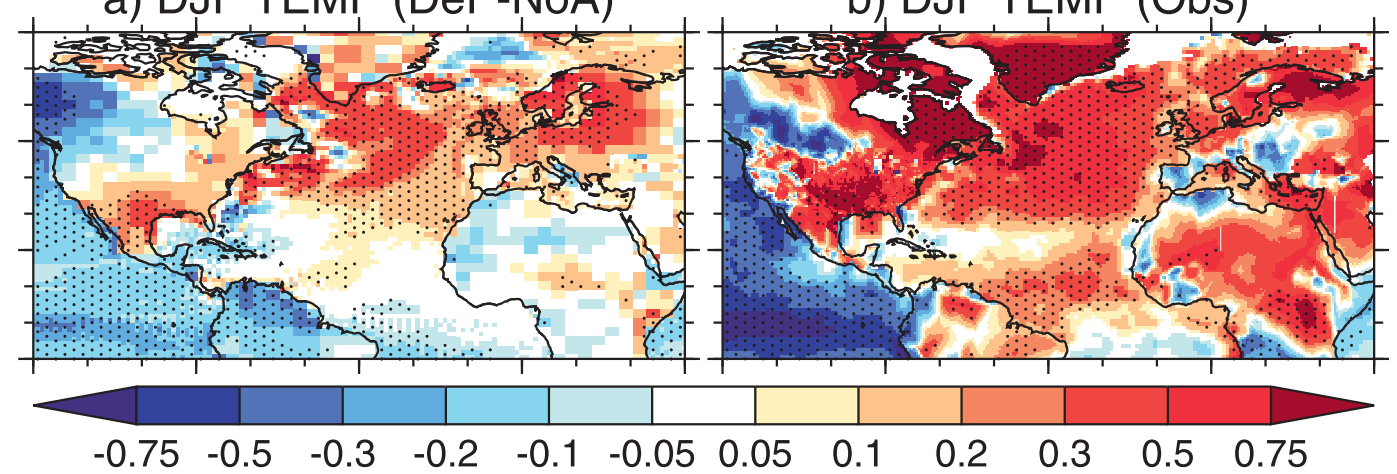

c) DJF SLP (DeP-NoA)

d) DJF SLP (Obs)

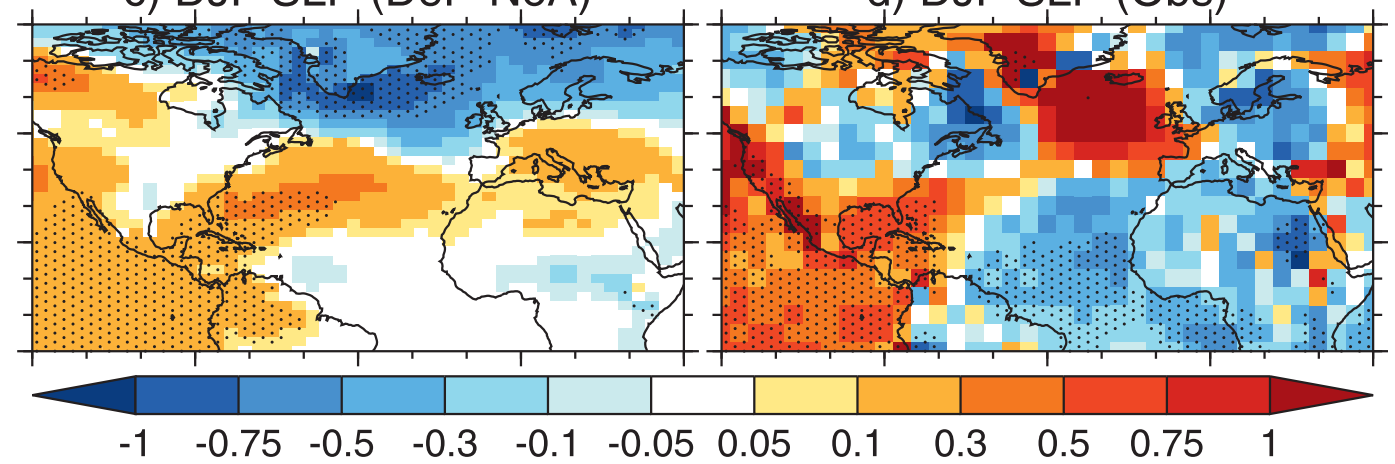

e) DJF PRECIP (DeP-NoA)

f) DJF PRECIP (Obs)

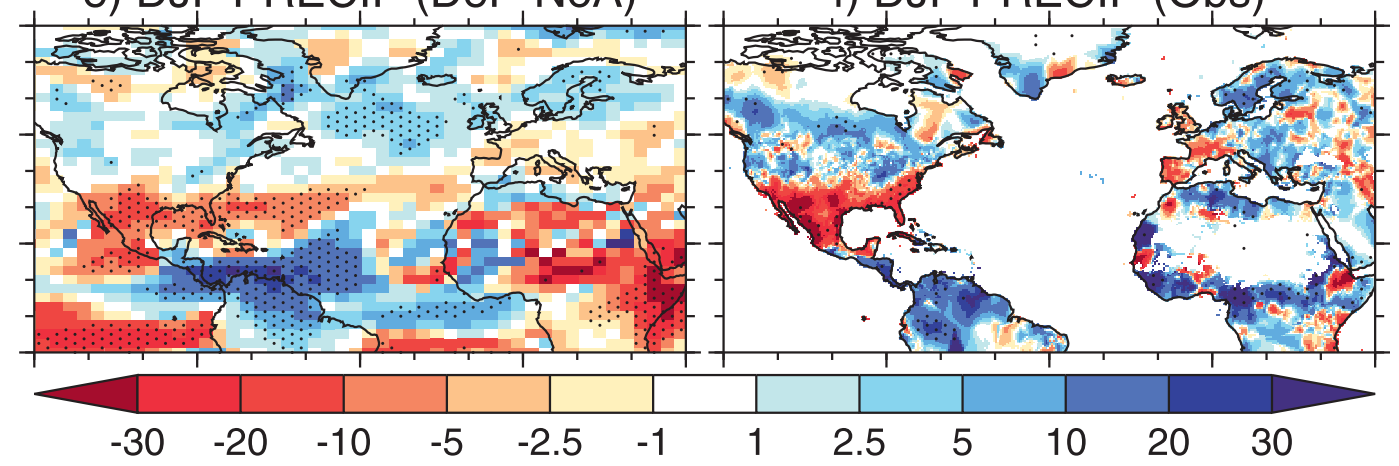

FIG. 2. Comparison of the predicted (years 2-6) and observed change in surface climate before and after the mid-1990s warming of the North Atlantic. (a) Difference in DJF SAT and SST $\left({ }^{\circ} \mathrm{C}\right)$ averaged over years 2-6 (i.e., the difference in SAT and SST in DePreSys hindcasts initialized in 1997-2005 minus years 2-6 from DePreSys hindcasts initialized from 1968 to 1990). Difference is then made relative to the same difference in NoAssim hindcasts. (b) Difference between 1999-2009 and 1970-94 for the observed DJF SAT and SST after trend has been removed from each grid point—-see text for details. (c),(d) and (e),(f) As in (a) and (b), but for SLP (hPa) and precipitation (\% of the mean) anomalies, respectively. Stippling shows where the differences are significant at the $p \leq 0.1$ level based on a two-sided Student's $t$ test.

\section{b. Surface variable climate impacts}

We now explore other societally relevant climate variables in the North Atlantic sector $\left(10^{\circ} \mathrm{S}-80^{\circ} \mathrm{N}, 130^{\circ} \mathrm{W}-\right.$ $\left.50^{\circ} \mathrm{E}\right)$ in forecast years 2-6. In December-February (DJF), DePreSys predicts significant SAT anomalies in North America and northern Europe (Fig. 2a) and substantial SLP anomalies that resemble a positive
North Atlantic Oscillation (NAO; Fig. 2c). Finally, significantly reduced rainfall is predicted over the southern United States and Mexico, and increased rainfall in Central America and northern South America (Fig. 2e), which is consistent with warm Atlantic SSTs in this model (Sutton and Hodson 2005; Knight et al. 2006). A weak increase in precipitation is also predicted over Scandinavia. The predictions of SAT agree with those 


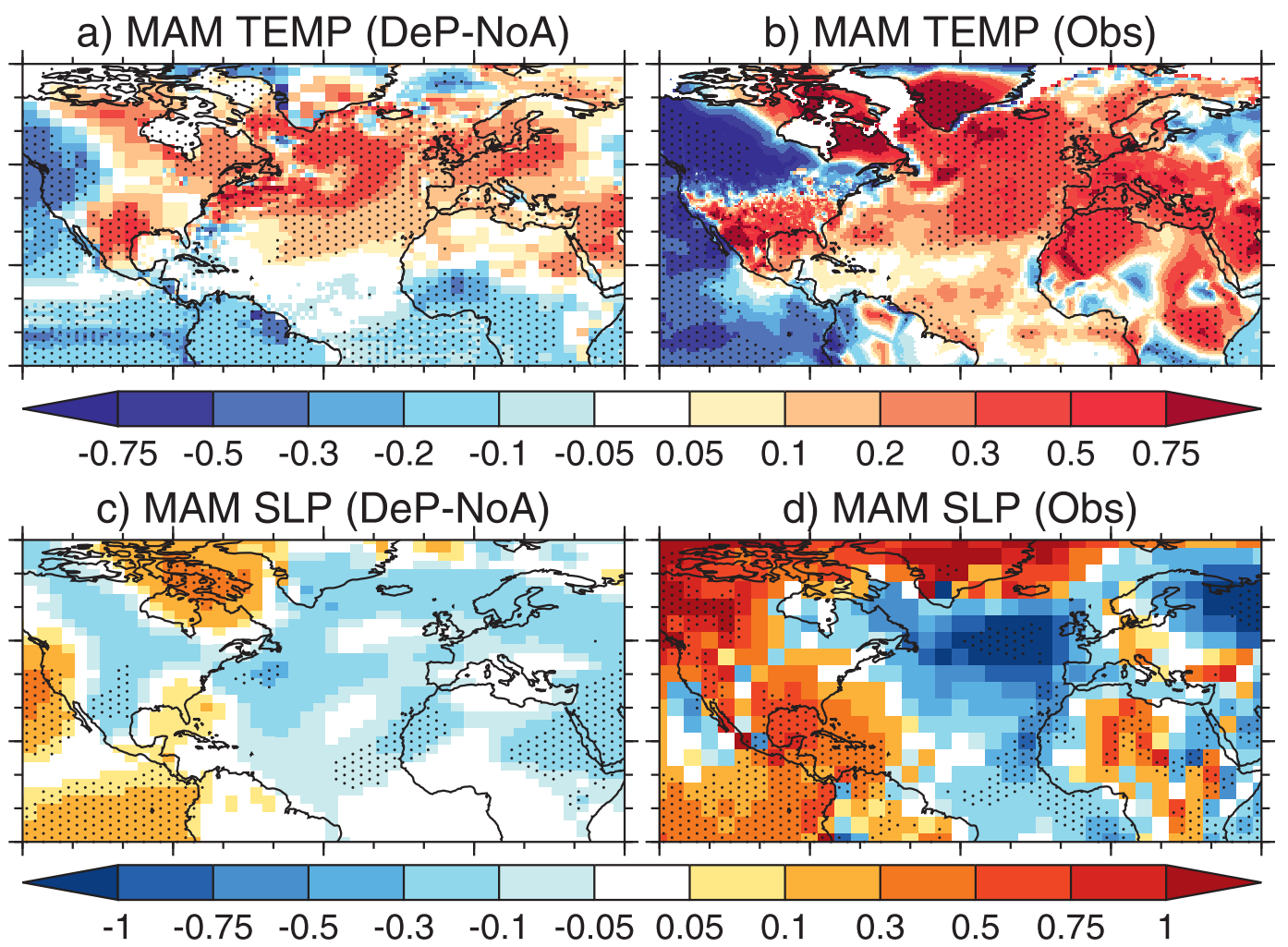

e) MAM PRECIP (DeP-NoA)

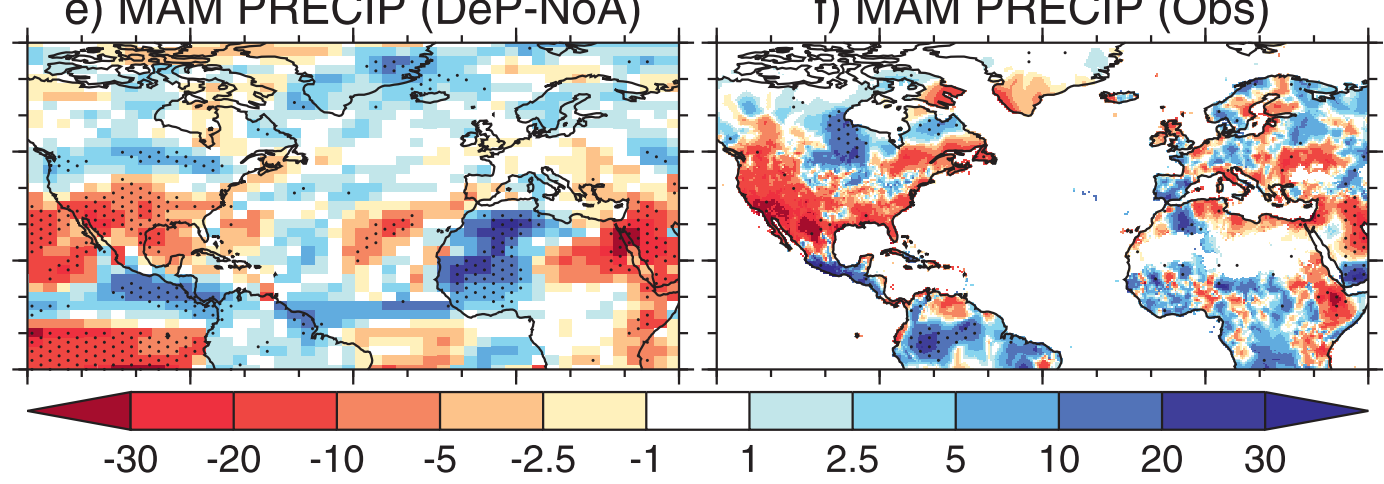

FIG. 3. As in Fig. 2, but for MAM.

observed in North America (Fig. 2b); however, DePreSys predicts the wrong sign of anomalies in southern Europe, which may be related to a poor prediction of SLP. The observations show high SLP over the eastern subpolar North Atlantic (Fig. 2d) and not a positive NAO, as in DePreSys. Finally, an observed reduction in rainfall over the southern United States and Mexico, and an increase in Central America and northern South America and Scandinavia (Fig. 2f), is similar to that predicted by DePreSys.

In March-May (MAM), DePreSys predicts significant warm SAT in western Europe, a dipole of SAT anomalies in western North America, and cool anomalies over the northern part of South America and central Africa
(Fig. 3a). A weak pattern of low pressure is present over the North Atlantic, North America, and Europe (Fig. 3c), and the pattern of rainfall in MAM (Fig. 3e) is similar to that seen in DJF (Fig. 2e). The pattern of SAT anomalies predicted by DePreSys (Fig. 3a) agrees well with those observed (Fig. 3b), especially the warm anomalies in western Europe, and the anomalies over the west of North America. The observed SLP is anomalously low over the Atlantic region (Fig. 3d); however, the reduction in observed SLP is greater than in DePreSys. Finally, the observed precipitation patterns over the Americas (Fig. 3f) are similar to those simulated by DePreSys.

In June-August (JJA; Fig. 4) and SeptemberNovember (SON; Fig. 5), DePreSys predicts significant 


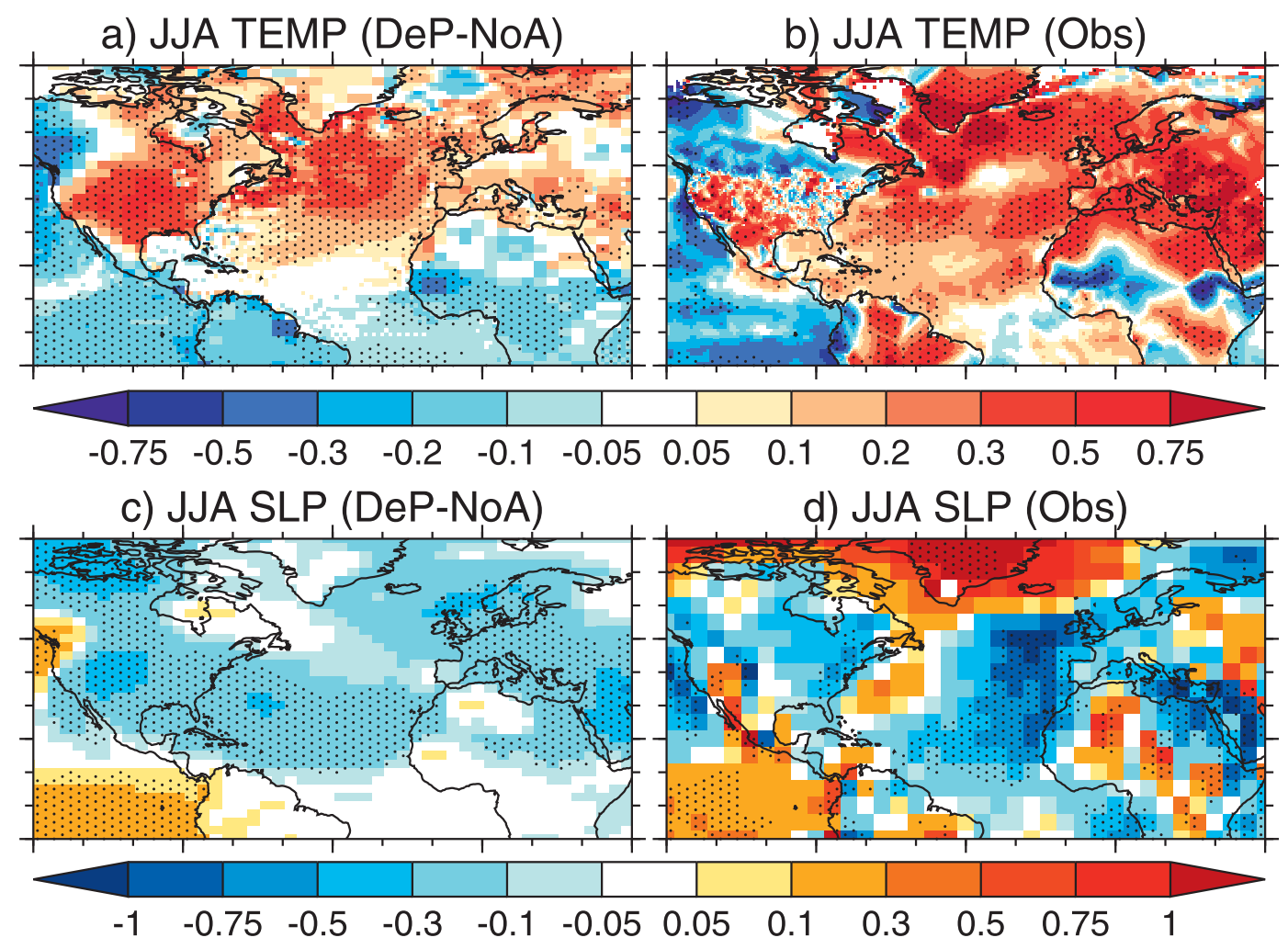

e) JJA PRECIP (DeP-NoA)

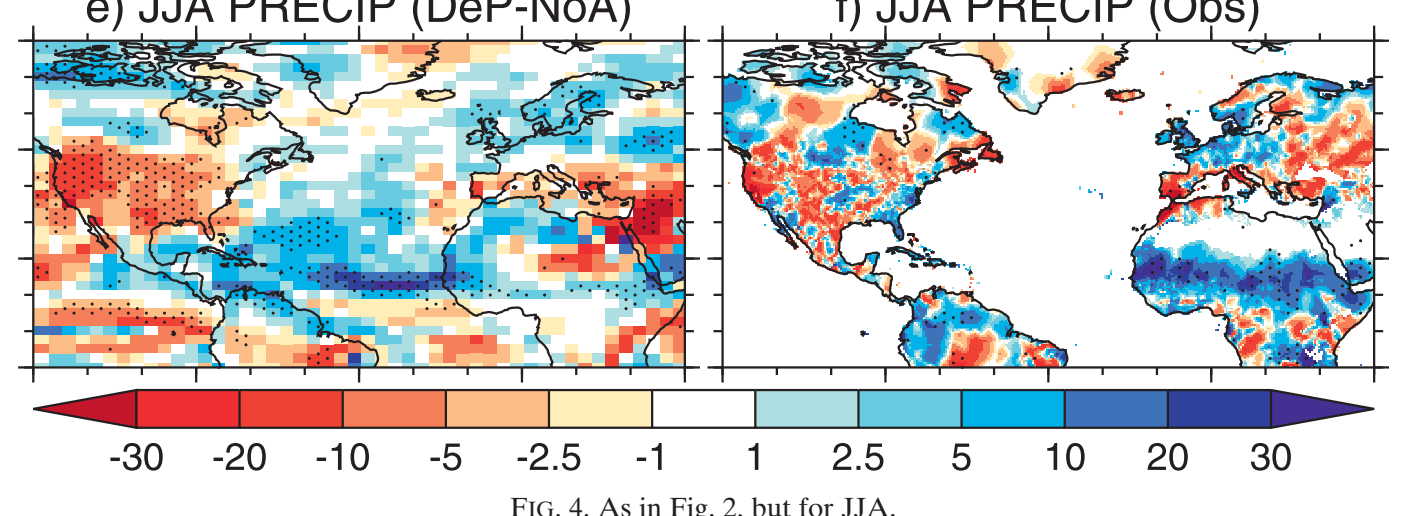

FIG. 4. As in Fig. 2, but for JJA.

warm SAT anomalies over much of the United States, cool SAT anomalies in northwestern North America and central Africa (Figs. 4a, 5a), and an extension of warm SST anomalies into the tropical North Atlantic in SON (Fig. 5a). Low SLP anomalies are predicted across North America, the subtropical North Atlantic, and Europe (Figs. 4c, 5c). Last, DePreSys predicts a significant reduction in rainfall over North America in JJA and SON (Figs. 4e, 5e) and a weak increase across northern Europe in JJA [Fig. 5e; which is significant when taking a box average (not shown)]. Again, the predicted SAT is in good agreement with the observed SAT anomalies (Figs. 4b, 5b) in North America and in central Africa.
However, DePreSys fails to predict the observed SAT increase in North Africa, South America, or eastern Europe. The low pressure anomalies in DePreSys (Figs. 4c, 5c) are similar to those observed (Figs. 4d, 5d), and are consistent with the model's response to warm North Atlantic SSTs (Sutton and Hodson 2005; Knight et al. 2006). Finally, the predicted reduction in rainfall over North America in JJA and SON (Figs. 4f, 5f), and an increase over northern Europe in JJA (Fig. 4f) are also observed. However, DePreSys does not capture the observed rainfall change in the Sahel (Figs. 4f, 5f), which is likely due to model bias in this region (Knight et al. 2006). 


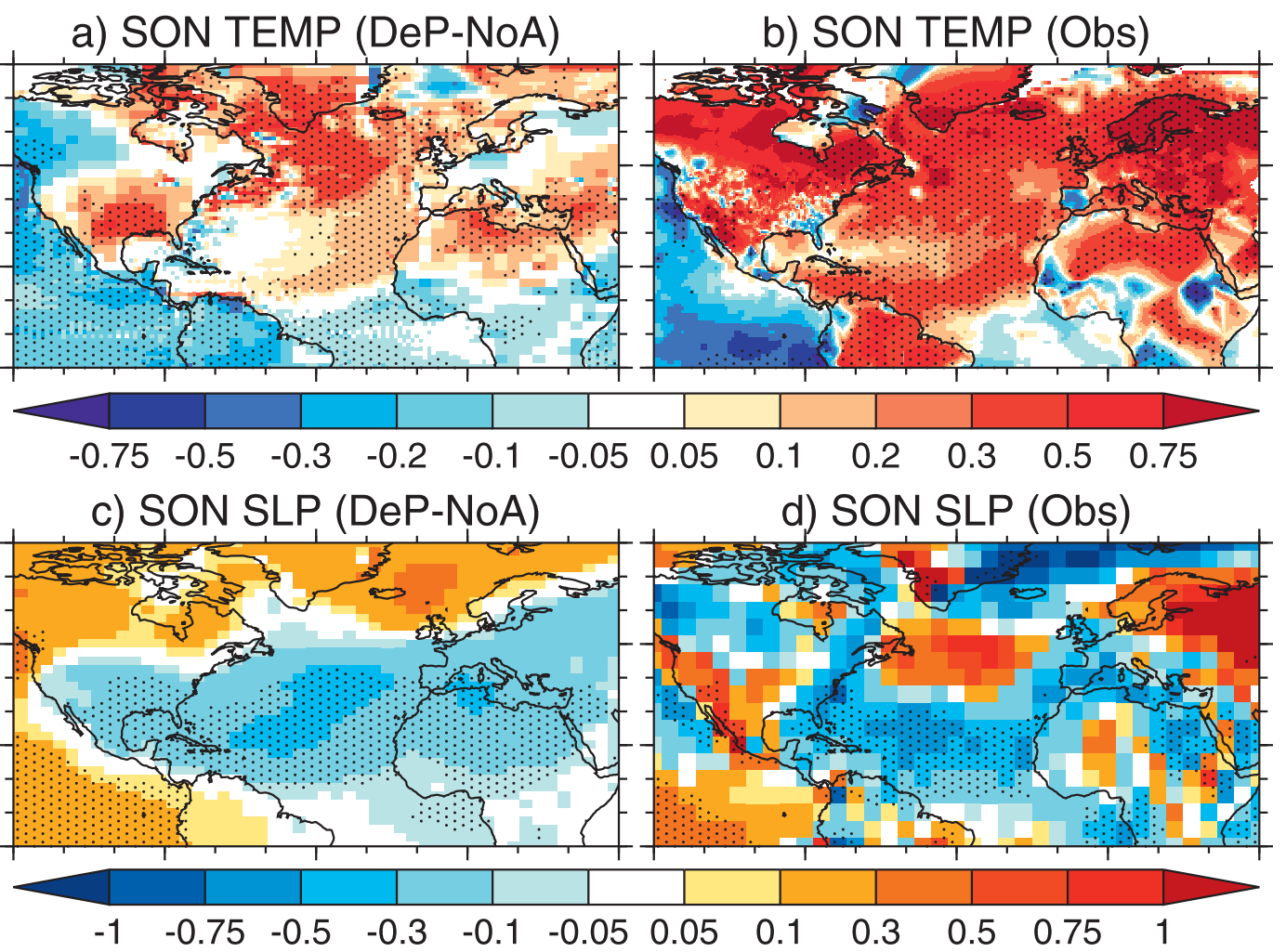

e) SON PRECIP (DeP-NoA)

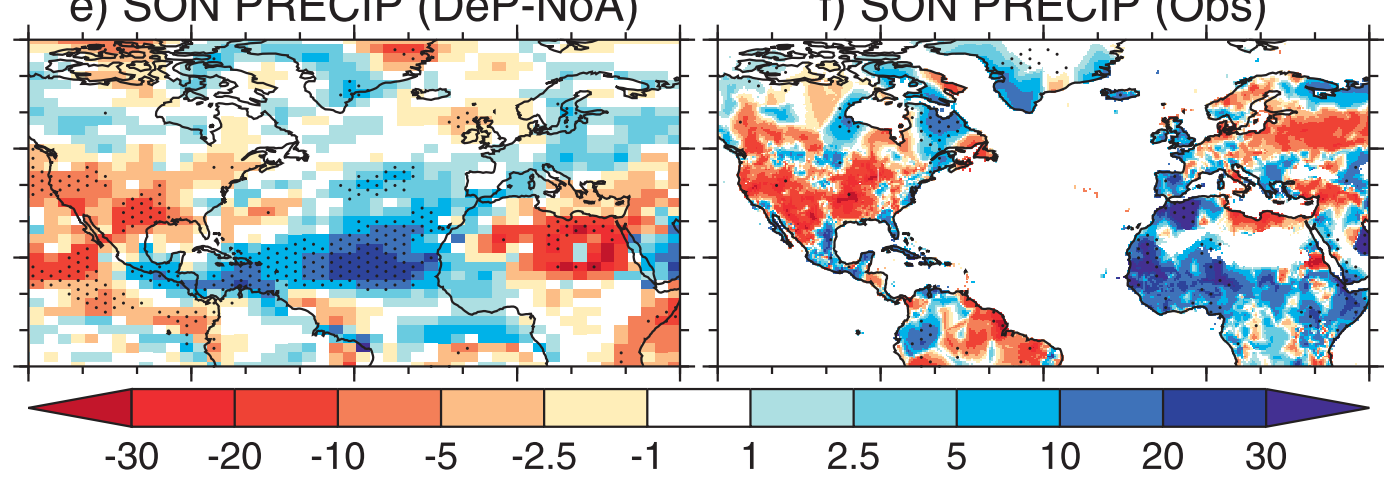

FIG. 5. As in Fig. 2, but for SON.

\section{Discussion: Pacific SSTs}

Many of the changes in surface variables predicted by DePreSys, especially those over the North American region, appear to be consistent with the impact of warm North Atlantic SSTs identified in previous research (Sutton and Hodson 2005, 2007; Knight et al. 2006; Kushnir et al. 2010; Hodson et al. 2010; Ting et al. 2011). However, it is well established that tropical Pacific SSTs can affect the North American and wider climate, especially via the excitation and propagation of Rossby waves (Trenberth and Branstator 1992; Robinson et al. 2002; Schubert et al. 2004, 2009; Seager et al. 2005a,b; Meehl et al. 2012). Figure 6 shows the difference in
250-hPa geopotential height (GEOPOT) for DePreSys hindcasts started before and after the mid-1990s Atlantic warming event relative to NoAssim for December-May (DJFMAM) and June-November (JJASON) so to minimize plots. In the North Pacific, a Rossby wave train is clear in both extended seasons (Figs. 6b,e), which forces a negative Pacific-North America (PNA) pattern. The predicted pattern of geopotential height anomalies agrees well with the National Centers for Environmental Prediction (NCEP) reanalysis (Fig. 6c) in DJFMAM, suggesting that the simulation by DePreSys is realistic. However, the agreement is not as good in JJASON (Fig. 6e). The Rossby wave train in DePreSys is consistent with forcing from SST and associated precipitation 
a) DJFMAM (DeP-NoA) PRECIP

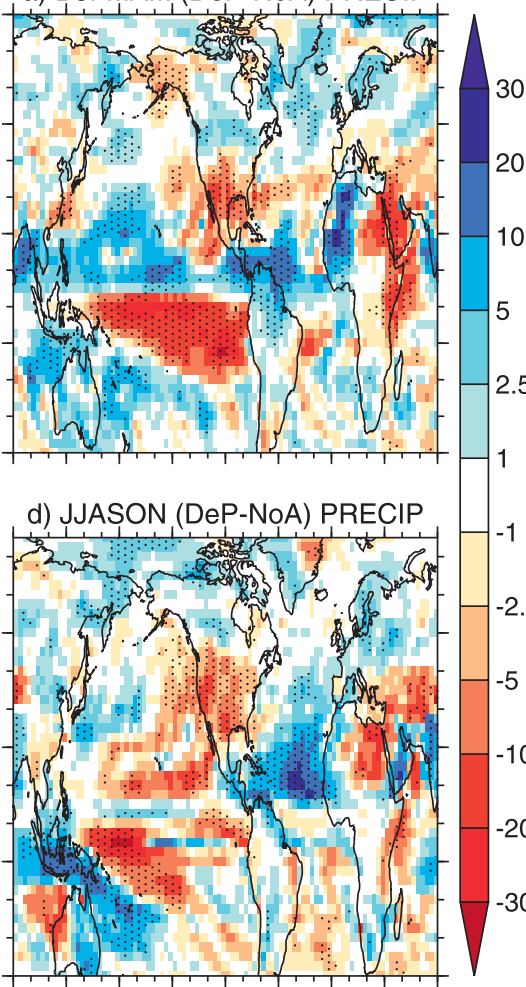

b) DJFMAM (DeP-NoA) GEOPOT

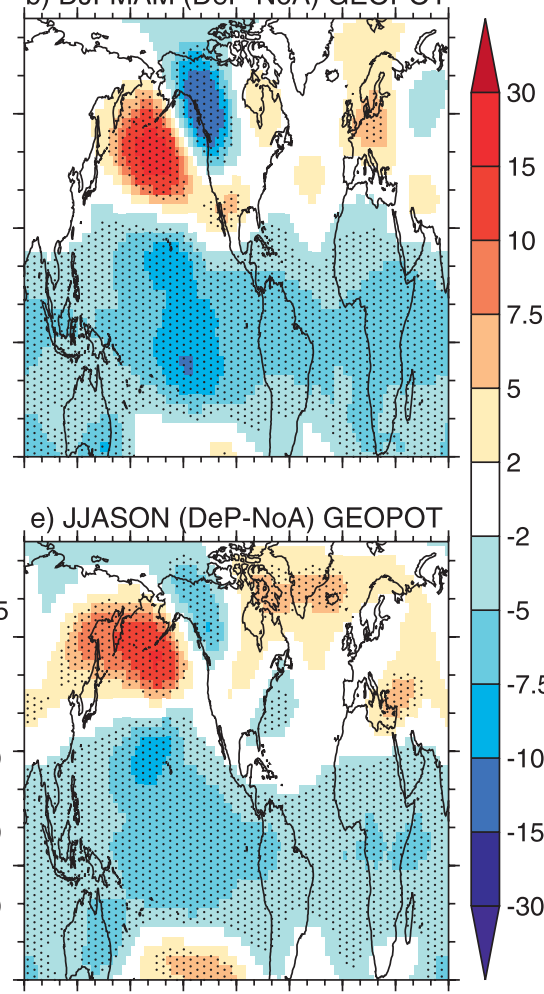

c) DJFMAM (NCEP) GEOPOT

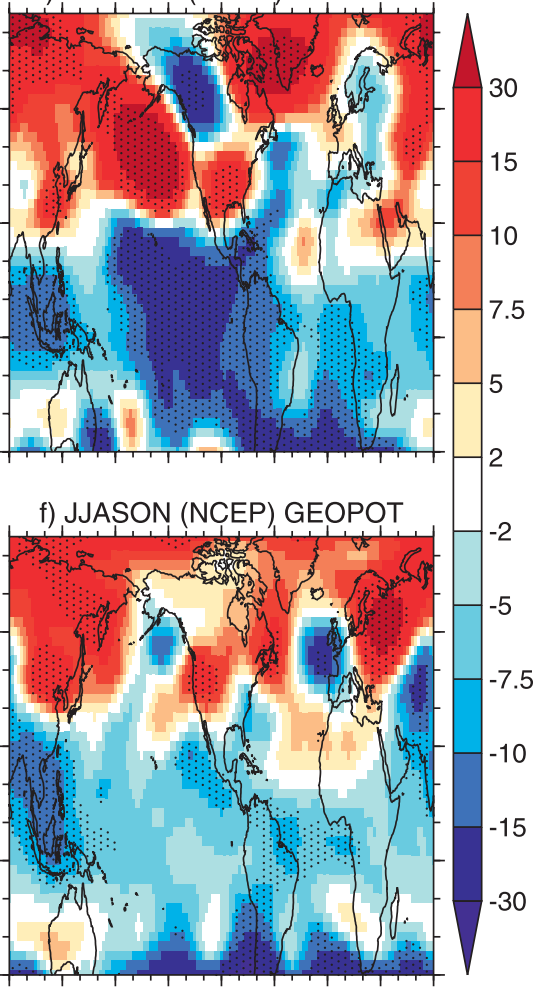

FIG. 6. Role of the Pacific in the predicted climate impacts over North America. (a) DJFMAM difference between precipitation (\% of the mean) averaged over years 2-6 from the DePreSys hindcasts initialized in 1997-2005 minus years 2-6 from DePreSys hindcasts initialized from 1968 to 1990 . Anomalies are relative to the same difference in NoAssim. (b) As in (a), but for the 250-hPa GEOPOT (m). (c) 1999-2009 mean 250-hPa GEOPOT from NCEP reanalysis minus 1970-94. Note that a trend is removed from each grid point from the NCEP data as other observed data (see text). (d)-(f) As in (a)-(c), but for JJASON. Stippling shows where anomalies are significant at the $p \leq 0.1$ based on a two-sided Student's $t$ test.

anomalies over the Pacific (Figs. 6a,d). Thus, Fig. 6 suggests that the Pacific SSTs exert an important influence on the North American climate in the DePreSys hindcasts initialized before and after the mid-1990s, similar to findings by previous studies (Seager et al. 2005b; Dai 2013; Meehl et al. 2012).

Finally, many studies suggest that Atlantic SST anomalies can influence Pacific SST (Dong et al. 2006; Sutton and Hodson 2007; Zhang and Delworth 2007; Kushnir et al. 2010; Kucharski et al. 2011; Chikamoto et al. 2012). Thus, the predicted Pacific SSTs in DePreSys could be a coupled response to warm Atlantic SSTs. However, given the proposed mechanisms of the IPO (Meehl and $\mathrm{Hu}$ 2006; Power and Colman 2006), it is possible that Pacific SST anomalies developed independently of the Atlantic. Further experiments are needed to elucidate any Atlantic influence on Pacific SSTs in these hindcasts.

\section{Conclusions}

This study has investigated the impact of initialization on predictions of changes in seasonal surface climate associated with the mid-1990s warming of the North Atlantic. To do so we analyzed results from the Met Office decadal prediction system (DePreSys), examining the differences between hindcasts initialized before and after the warming, relative to the differences found in hindcasts initialized without the use of observations. By focusing on forecast years $2-6$, we have demonstrated that the impact of initialization lasts beyond the first year, even over land. The main results are as follows:

- DePreSys successfully predicts the persistence and development of the global pattern of sea surface temperature (SST) anomalies over forecast years 2-6 following the mid-1990s-particularly, warm anomalies in the North Atlantic and cool anomalies in the tropical eastern Pacific.

- Associated with the SST anomalies, DePreSys predicts significant anomalies in the surface climate over land as well as ocean in all seasons-specifically, anomalies in surface air temperature (SAT), sea level pressure (SLP), and precipitation over North America, northwestern Europe, and the tropical North Atlantic. 
- Many predicted anomalies are similar to those observed, especially warm and dry conditions over North America in all seasons, low SLP and increased rainfall over northern Europe in JJA, and mild temperatures over western Europe in MAM. DePreSys also captures low SLP and increased rainfall in the tropics. However, DePreSys does not predict all the observed anomalies, especially over Europe in DJF, where DePreSys predicts the wrong sign of the North Atlantic Oscillation. Such errors highlight the need to improve the models used for near-term climate prediction.

- The predicted anomalies in SAT and precipitation over North America are consistent with those related to warm North Atlantic SSTs in the model (Sutton and Hodson 2005; Knight et al. 2006). However, it is demonstrated that the Pacific SST anomalies also play a role in the DePreSys predictions of surface climate over North America.

The similarity of the simulated changes with that observed provides further evidence that the changes in the ocean played a significant role in the observed decadal variability of surface climate variables and, importantly, gives encouragement for the prospects of providing useful near-term predictions of climate variables over land. The results also suggest that changes in SST in both the Atlantic and in the Pacific during the mid-1990s were important for surface climate impacts, particularly over North America. Therefore, this study highlights the need for future research to address, for example, the relative role of Atlantic and Pacific SST anomalies for the predicted impacts, and the origin of skill in predicting the Pacific SSTs. Finally, we believe that the case study approach is a fruitful one for making progress in understanding the capabilities and limitations of decadal climate prediction systems. Distinguishing the role of model errors from errors in initialization and other sources is a difficult challenge; in this context, it would be valuable to repeat our study using results from other systems and to apply a similar approach to other case studies.

Acknowledgments. We thank Dan Hodson, Buwen Dong, Mike Blackburn, and Ed Hawkins for the valuable discussion. JR acknowledges support from the National Environment Research Council (NERC)-funded Value of the RAPID array for climate predictions (VALOR) project (NE/G007845/1), and from the Prévisibilité Climatique Decennale (PRECLIDE) project, which was funded by the BNP Paribas Foundation. RS is funded by NCAS-Climate. DS was supported by the U.K. Joint Department of Energy \& Climate Change (DECC)/Department for Environment, Food and Rural Affairs (Defra) Met Office Hadley Centre Climate Programme (GA01101) and the European Community's
Seventh Framework Programme under the Thermohaline Overturning-At Risk? (THOR) and Comprehensive Modelling of the Earth System for Better Climate Prediction and Projection (COMBINE) projects. We thank the anonymous reviewers for their useful comments.

\section{REFERENCES}

Allan, R., and T. Ansell, 2006: A new globally complete monthly historical gridded mean sea level pressure dataset (HadSLP2): 1850-2004. J. Climate, 19, 5816-5842.

Booth, B. B. B., N. J. Dunstone, P. R. Halloran, T. Andrews, and N. Bellouin, 2012: Aerosols implicated as a prime driver of twentieth-century North Atlantic climate variability. Nature, 484, 228-232, doi:10.1038/nature10946.

Burgman, R. J., A. C. Clement, C. M. Mitas, J. Chen, and K. Esslinger, 2008: Evidence for atmospheric variability over the Pacific on decadal timescales. Geophys. Res. Lett., 35, L01704, doi:10.1029/ 2007 GL031830.

Chen, J., A. Del Genio, B. Carlson, and M. Bosilovich, 2008: The spatiotemporal structure of twentieth-century climate variations in observations and reanalyses. Part II: Pacific pandecadal variability. J. Climate, 21, 2634-2650.

Chikamoto, Y., M. Kimoto, M. Watanabe, M. Ishii, and T. Mochizuki, 2012: Relationship between the Pacific and Atlantic stepwise climate change during the 1990s. Geophys. Res. Lett., 39, L21710, doi:10.1029/2012GL053901.

Collins, M., B. B. B. Booth, G. Harris, J. Murphy, D. Sexton, and M. Webb, 2006: Towards quantifying uncertainty in transient climate change. Climate Dyn., 27, 127-147.

Dai, A., 2013: The influence of the inter-decadal Pacific oscillation on US precipitation during 1923-2010. Climate Dyn., 41, 633-646, doi:10.1007/s00382-012-1446-5.

Dong, B., R. T. Sutton, and A. A. Scaife, 2006: Multidecadal modulation of El Niño-Southern Oscillation (ENSO) variance by Atlantic Ocean sea surface temperatures. Geophys. Res. Lett., 33, L08705, doi:10.1029/2006GL025766.

Forster, P., and Coauthors, 2007: Changes in atmospheric constituents and in radiative forcing. Climate Change 2007: The Physical Science Basis, S. Solomon et al., Eds., Cambridge University Press, 131-234.

Hodson, D., R. Sutton, C. Cassou, N. Keenlyside, Y. Okumura, and T. Zhou, 2010: Climate impacts of recent multidecadal changes in Atlantic Ocean sea surface temperature: A multimodel comparison. Climate Dyn., 34, 1041-1058.

Johns, T. C., and Coauthors, 2003: Anthropogenic climate change for 1860 to 2100 simulated with the HadCM3 model under updated emissions scenarios. Climate Dyn., 20, 583-612.

Keenlyside, N. S., M. Latif, J. Jungclaus, L. Kornblueh, and E. Roeckner, 2008: Advancing decadal-scale climate prediction in the North Atlantic sector. Nature, 453, 84-88, doi:10.1038/ nature 06921 .

Kim, H.-M., P. J. Webster, and J. A. Curry, 2012: Evaluation of short-term climate change prediction in multi-model CMIP5 decadal hindcasts. Geophys. Res. Lett., 39, L10701, doi:10.1029/ 2012GL051644.

Knight, J. R., C. K. Folland, and A. A. Scaife, 2006: Climate impacts of the Atlantic multidecadal oscillation. Geophys. Res. Lett., 33, L17706, doi:10.1029/2006GL026242.

Kucharski, F., I.-S. Kang, R. Farneti, and L. Feudale, 2011: Tropical Pacific response to 20th century Atlantic warming. Geophys. Res. Lett., 38, L03702, doi:10.1029/2010GL046248. 
Kushnir, Y., R. Seager, M. Ting, N. Naik, and J. Nakamura, 2010: Mechanisms of tropical Atlantic SST influence on North American precipitation variability. J. Climate, 23, 5610-5628.

Lee, T., and M. J. McPhaden, 2008: Decadal phase change in largescale sea level and winds in the Indo-Pacific region at the end of the 20th century. Geophys. Res. Lett., 35, L01605, doi:10.1029/2007GL032419.

MacLeod, D. A., C. Caminade, and A. P. Morse, 2012: Useful decadal climate prediction at regional scales? A look at the ENSEMBLES stream 2 decadal hindcasts. Environ. Res. Lett., 7, 044012, doi:10.1088/1748-9326/7/4/044012.

Meehl, G. A., and A. Hu, 2006: Megadroughts in the Indian monsoon region and southwest North America and a mechanism for associated multidecadal Pacific sea surface temperature anomalies. J. Climate, 19, 1605-1623.

— hindcasts and predictions for the Pacific region. Geophys. Res. Lett., 39, L22705, doi:10.1029/2012GL053423.

_ , and Coauthors, 2009: Decadal prediction: Can it be skillful? Bull. Amer. Meteor. Soc., 90, 1467-1485.

_ _ J. Arblaster, and G. Branstator, 2012: Mechanisms contributing to the warming hole and the consequent U.S. east-west differential of heat extremes. J. Climate, 25, 6394-6408.

Mitchell, T., and P. Jones, 2005: An improved method of constructing a database of monthly climate observations and associated high-resolution grids. Int. J. Climatol., 25, 693-712.

Mochizuki, T., and Coauthors, 2010: Pacific decadal oscillation hindcasts relevant to near-term climate prediction. Proc. Natl. Acad. Sci. USA, 107, 1833-1837.

_- and Coauthors, 2012: Decadal prediction using a recent series of MIROC global climate models. J. Meteor. Soc. Japan, 90, 373-383.

Newman, M., G. Compo, and M. Alexander, 2003: ENSO-forced variability of the Pacific decadal oscillation. J. Climate, 16, 3853-3857.

Peterson, W T., and F. B. Schwing, 2003: A new climate regime in northeast Pacific ecosystems. Geophys. Res. Lett., 30, 1896, doi:10.1029/2003GL017528.

Pohlmann, H., J. H. Jungclaus, A. Köhl, D. Stammer, and J. Marotzke, 2009: Initializing decadal climate predictions with the GECCO oceanic synthesis: Effects on the North Atlantic. J. Climate, 22, 3926-3938.

Power, S., and R. Colman, 2006: Multi-year predictability in a coupled general circulation model. Climate Dyn., 26, 247-272.

— , T. Casey, C. Folland, A. Colman, and V. Mehta, 1999: Interdecadal modulation of the impact of ENSO on Australia. Climate Dyn., 15, 319-324.

Rayner, N., D. Parker, E. Horton, C. Folland, L. Alexander, D. Rowell, E. Kent, and A. Kaplan, 2003: Global analyses of sea surface temperature, sea ice, and night marine air temperature since the late nineteenth century. J. Geophys. Res., 108, 4407, doi:10.1029/2002JD002670.

Robinson, W., R. Reudy, and J. Hansen, 2002: General circulation model simulations of recent cooling in the east-central United States. J. Geophys. Res., 107, 4748, doi:10.1029/2001JD001577.

Robson, J. I., 2010: Understanding the performance of a decadal prediction system. Ph.D. thesis, University of Reading, $233 \mathrm{pp}$.

— - R. T. Sutton, K. Lohmann, D. Smith, and M. Palmer, 2012a: Causes of the rapid warming of the North Atlantic Ocean in the mid-1990s. J. Climate, 25, 4116-4134.

,-- , and D. M. Smith, 2012b: Initialized predictions of the rapid warming of the North Atlantic Ocean in the mid 1990s. Geophys. Res. Lett., 25, L19713, doi:10.1029/2012GL053370.
Schubert, S., M. Suarez, P. Pegion, R. Koster, and J. Bacmeister, 2004: Causes of long-term drought in the U.S. Great Plains. J. Climate, 17, 485-503.

— , and Coauthors, 2009: A U.S. CLIVAR project to assess and compare the responses of global climate models to droughtrelated SST forcing patterns: Overview and results. J. Climate, 22, 5251-5272.

Seager, R., N. Harnik, W. A. Robinson, Y. Kushnir, M. Ting, H.-P. Huang, and J. Velez, 2005a: Mechanisms of ENSO-forcing of hemispherically symmetric precipitation variability. Quart. J. Roy. Meteor. Soc., 131, 1501-1527.

—, Y. Kushnir, C. Herweijer, N. Naik, and J. Velez, 2005b: Modeling of tropical forcing of persistent droughts and pluvials over western North America: 1856-2000. J. Climate, 18, 4065-4088.

Smith, D. M., and J. M. Murphy, 2007: An objective ocean temperature and salinity analysis using covariances from a global climate model. J. Geophys. Res., 112, C02022, doi:10.1029/ 2005JC003172.

, S. Cusack, A. W. Colman, C. K. Folland, G. R. Harris, and J. M. Murphy, 2007: Improved surface temperature prediction for the coming decade from a global climate model. Science, 317, 796-799, doi:10.1126/science.1139540.

, R. Eade, N. J. Dunstone, D. Fereday, J. M. Murphy, H. Pohlmann, and A. A. Scaife, 2010: Skilful multi-year predictions of Atlantic hurricane frequency. Nat. Geosci., 3, 846849, doi:10.1038/ngeo1004.

Sutton, R. T., and D. L. R. Hodson, 2005: Atlantic Ocean forcing of North American and European summer climate. Science, 309, 115-118, doi:10.1126/science.1109496.

— cooling of the North Atlantic Ocean. J. Climate, 20, 891-907. , and B. Dong, 2012: Atlantic Ocean influence on a shift in European climate in the 1990s. Nat. Geosci., 5, 788-792, doi:10.1038/NGEO1595.

Ting, M., Y. Kushnir, R. Seager, and C. Li, 2011: Robust features of Atlantic multi-decadal variability and its climate impacts. Geophys. Res. Lett., 38, L17705, doi:10.1029/2011GL048712.

Trenberth, K., and G. Branstator, 1992: Issues in establishing causes of the 1988 drought over North America. J. Climate, 5, 159-172.

Uppala, S. M., and Coauthors, 2005: The ERA-40 Re-Analysis. Quart. J. Roy. Meteor. Soc., 131, 2961-3012.

van Oldenborgh, G., F. Doblas-Reyes, B. Wouters, and W. Hazeleger, 2012: Decadal prediction skill in a multi-model ensemble. Climate Dyn., 38, 1263-1280.

Wang, H., S. Schubert, M. Suarez, J. Chen, M. Hoerling, A. Kumar, and P. Pegion, 2009: Attribution of the seasonality and regionality in climate trends over the United States during 1952000. J. Climate, 22, 2571-2590.

Wittenberg, A. T., 2009: Are historical records sufficient to constrain ENSO simulations. Geophys. Res. Lett., 36, L12702, doi:10.1029/2009GL038710.

Yeager, S., A. Karspeck, G. Danabasoglu, J. Tribbia, and H. Teng, 2012: A decadal prediction case study: Late twentieth-century North Atlantic Ocean heat content. J. Climate, 25, 5173-5189.

Zhang, R., and T. L. Delworth, 2006: Impact of Atlantic multidecadal oscillation on India/Sahel rainfall and Atlantic hurricanes. Geophys. Res. Lett., 33, L17712, doi:10.1029/2006GL026267.

- and — 2007: Impact of the Atlantic multidecadal oscillation on North Pacific climate variability. Geophys. Res. Lett., 34, L23708, doi:10.1029/2007GL031601.

Zwiers, F., and H. von Storch, 1995: Taking serial correlation into account in tests of the mean. J. Climate, 8, 336-351. 